\title{
EFICÁCIA DO ALBENDAZOL NO TRATAMENTO DA ENTEROBÍASE
}

\author{
Vicente AMATo NETo (1), Vera Lucia Pagliusi CASTILHO (2), Antonio Augusto Baillot MOREIRA (2), \\ Eunice José de SANT'ANa (2), Pedro Luiz Silva PINTo (2), Rubens CalMPOS (2) e \\ Liliana Aparecida Araújo PADILHa (2)
}

\section{R E S U M O}

Verificaram os Autores que o albendazol é muito eficiente no tratamento da enterobiase. Usando dose única de $10 \mathrm{mg} / \mathrm{kg}$, obtiveram $100 \%$ de curas quando administraram esse anti-helmíntico a 29 crianças. Foi comprovada tolerância bastante satisfatória e o estudo rèalizado contribuiu para a melhor demarcação do espectro de atividade antiparasitária do composto referido.

\section{N T R O D U G A O}

A enterobíase, infecção parasitária causada pelo Enterobius vermicularis, é bastante frequiente no Brasil e em vários outros países. $O$ tratamento específico a ela pertinente pode ser, atualmente, realizado de maneira efetiva e simples, por meio de diversos medicamentos, entre os quais merecem destaque o mebendazol, o pamoato de pirantel e o pamoato de pirvínio.

$O$ albendazol (metil 5 propiltiobenzimidazol-2-carbamato), novo composto anti-helmínti$\mathrm{co}$, vem tendo seu espectro de atividade demarcado através de múltiplas pesquisas e, no que concerne a verminoses intestinais humanas, já ficou demonstrado que ele é eficiente para debelar a ancilostomíase e a ascaridiase, afigurando-se menos valioso em relação à tricocefalíase $2,3,5,6,7,899,10$. Quanto à estrongiloidíase, 0 resultado terapêtico obtido foi, todavia, desanimador ${ }^{4}$.

Nesse contexto, torna-se sem dúvida conveniente procurar definir se a enterobiase é curável pelo albendazol, sobretudo diante da circunstância antes lembrada, ou seja, a expressiva prevalência a ela pertinente.
Os informes consignados na presente publicação dizem respeito a estudo que teve nexo com a necessidade citada no parágrafo anterior, convindo frisar que, precedentemente não aconteceram, a respeito, investigações conclusivas.

\section{MATERIAL E MÉTODOS}

Tratamos 29 crianças, dos sexos masculino e feminino e com idades de um a 11 anos, residentes em núcleo habitacional denominado Reino da Garotada de Poá, situado no Município de Poá (Estado de São Paulo). A enterobíase havia sido diagnosticada poucos dias antes, através do método da fita adesiva de celofane.

Usamos dose única de $10 \mathrm{mg} / \mathrm{kg}$, administrada pela via oral, cerca de uma hora após a refeição matinal. Empregamos comprimidos fracionáveis com $400 \mathrm{mg}\left({ }^{*}\right)$ e, como controle, praticamos sete avaliações, em igual número de dias sucessivos, desde uma semana depois do tratamento. A validade dessa forma de agir

(*) Medicamento fornecido pela firma "Searle do Brasil S/A" (São Paulo, Brasil).

Hospital das Clínicas, da Faculdade de Medicina da Universidade de São Paulo. Laboratório de Investigação Mé. dica - Parasitologia

(1) Chefe do Laboratório de Investigação Médica - Parasitologia

(2) Membro do Laboratório de Investigação Médica - Parasitologia 
AMATO NETO. V.; CASTILHO, V. L. P.; MOREIRA, A. A. B.; SANT'ANA, E. J. de; PINTO, P. L. S.; CAMPOS, R. \& PADILHA, L. A. A. - Eficácia do albendazol no tratamento da enterobíase. Rev. Inst. Med. trop. São Paulo 27:143-144, 1985.

e detalhes acerca da técnica parasitológica adotada encontram-se especificados em compêndio especializado ${ }^{1}$.

\section{RESULTADOS}

Verificamos que, valorizado o critério adotado, sucederam $100 \%$ de curas, uma vez que nenhum dos exames efetuados após o emprego do albendazol mostrou ovos de $\mathbf{E}$. vermicularis.

A tolerância ao remédio utilizado pôde ser considerada como muito satisfatória, pois não tiveram lugar manifestações colaterais dignas de menção.

\section{DISGUSSÃO}

Diante do exposto, é possível deduzir facilmente que o albencazol mostrou-se muito apto a combater a enterobiase, tendo revelado possuir outras virtudes suplementares: boa tolerância por parte dos indivíduos medicados e capacidade curativa de posologia singela.

Essas conclusões permitem incorporar o composto em questão à primeira linha dos recursos terapêuticos que se opõem à infecção devida ao $\mathbf{E}$. vermicularis.

F apropriado, a seguir, tentar conseguir êxito semelhante com prescrição de quantidade menor do remédio, a fim de consumar vantagem sob o ponto de vista econômico.

\section{SUMMARY}

\section{Efficacy of albendazole in the treatment of enterobiasis}

Albendazole was shown to be very effective in the treatment of enterobiasis. A cure rate of $100 \%$ was noticed, when a single dose of 10 $\mathrm{mg} / \mathrm{kg}$ 'was given to 29 children. The drug was quite well tolerated by all recipients. This trial has brought additional evidence of the efficacy of albendazole as an antihelminthic agent, contributing to the proper establishment of its spectrum of activity.

\section{REFERENCIAS BIBLIOGRAFICAS}

1. AMATO NETO, V. \& CORREA, L. L. - Exame Parasitológico das Fezes. São Paulo, Sarvier, 1980.

2. AMATO NETO, V.; MOREIRA, A. A. B.; CAMPOS, R.; LAZZARO, E. S. M.; CHIARAMELII, M. C. G.; CASTILHO, V. L. P.; GOMES, A. E. C. \& PINTO, P. L. S. - Tratamento da ancilostomiase por meio do albendazol. Rev. Inst. Med. trop. São Paulo 25: 42-46, 1983.

3. AMATO NETO, V.; MOREIRA, A. A. B.; CAMPOS, R.; LAZZARO, E. S. M.; CHIARAMELLI, M. C. G.; PINTO, P. L. S.; NISHIOKA, S. A.; LEITE, R. M. \& SILVA, G. R. - Tratamento da ancilostomíase, ascaridíase e tricocefalíase por meio do albendazol ou do mebendazol. Rev. Inst. Med. trop. São Paulo 25: 294-299, 1983.

4. AMATO NETO, V.; MOREIRA, A. A. B.; CHIARAMELLI, M. C. G.; LEME, J. M. T. P.; CHIARAMELLI, D. R.; CAMPOS, R.; PINTO, P. L. S.; SANT'ANA, E. J. \& ROCHA, S. - Demarcação da atividade antihelmíntica do albendazol: estudo referente à estrongiloidíase humana. Rev. Inst. Med. trop. São Paulo 27: 95-98, 1985.

5. BARANSKI, M. C.; SILVA, A. F. \& GUIMARAEES, L. M. - Tratamiento de las helmintiasis intestinales con albendazol, un nuevo antihelmintico del grupo de los benzimidazoles. Estudio doble ciego. Comp. Invest. Clín. Latinoamer. 1 (Suppl. 1): 82-89, 1981.

6. CAMILO-COURA, L.; SOLI, A. S. V. \& WILLCOX, H. P. F. - Ensayo con albendazol en el tratamiento de las helmintiasis intestinales de los niños. Comp. Invest. Clín. Latinoamer. 1 (Suppl. 1): 75.81, 1981.

7. CAMPOS, R.; MOREIRA, A. A. B!; CASTILHO, V. L. P.; AMATO NETO, V.; GUIZELINI, E. \& PINTO, P. L. S. - Tratamento da ascaridíase e da tricocefaliase por meio do albendazol. Arq. Brasil. Med. 57: 185. 186, 1983.

8. PENE, P.; MOJON, M.; GARIN, J. P.; COULAUD, J. P. \& ROSSIGNOL, J. F. - Albendazole: a new broad spectrum anthelmintic. Double-blind multicenter clinical trial. Am. J. Trop. Med. Hyg. 31: 263-266, 1982.

9. ROSSIGNOL, J. F. - Albendazol: estudios clínicos realizados en Francia y Africa Occidental. Informe sobre 1.034 casos. Comp. Invest. Clín. Latinoamer. 1 (Suppl. 1): $117-125,1981$.

10. SCHETTINO. P. M. S. \& ORTEGA, I. H. - Ensayo clínico doble ciego con albendazol en México. Comp. Invest. Clín. Latinoamer. 1 (Suppl. 1): 90-98, 1981.

Recebido para publicação em 10/1/1985. 